\title{
Research and Implementation of the Construction of Embedded Technology Applied Curriculum Group for Professional Ability Training
}

\author{
Tang Ming ${ }^{1, *}$
}

\author{
Xi'an Peihua University, Xi'an 710125, China \\ *Corresponding author.Email: tangming@peihua.edu.cn
}

\begin{abstract}
With the rapid development of embedded technology, it has merged many disciplines such as computer science and technology, electronic information engineering, communication engineering, Internet of Things engineering. The construction of embedded technology curriculum system has lagged behind the development of society's demand for embedded technology talents. The content of traditional embedded technology courses is outdated, the curriculum is more scattered, and lacks systematisms. This topic analyzes the job requirements of embedded jobs in the current society, analyzes the job content and professional standards corresponding to the corresponding jobs through job tasks, according to the job requirements the knowledge points and skill points required by the professional standards extend the corresponding courses and hours, and finally form a curriculum group for the application of embedded technology.
\end{abstract}

Keywords: professional ability training; curriculum group; embedded technology.

\section{Background}

In October 2019, the Ministry of Education issued the "Opinions on Deepening the Reform of Undergraduate Education and Teaching and Comprehensively Improving the Quality of Talent Cultivation", which clearly stated that the quality of curriculum construction should be comprehensively improved, based on economic and social development needs and talent training goals, and strengthening the curriculum system. The overall design improves the planning and systematicity of the course construction and avoids randomization and fragmentation. It can be seen that, facing the tide of higher education reform in the new era, the Ministry of Education has put forward clear requirements for the quality of classroom teaching in undergraduate colleges and universities, and brought the importance of curriculum construction to a new height. In recent years, in accordance with the new requirements of the national comprehensive reform of higher education, the application-oriented curriculum construction has achieved more results around the cultivation of applied technical talents. However, a single applied course is only a "point", which conforms to the laws of engineering education and engineering logic, and an applied course group with a coherent relationship is the "face". At present, the development of the application-oriented curriculum group has become a key link and an inevitable requirement to promote the further reform of the school's application-oriented curriculum.

With the rapid development of electronics and information technology[1], embedded technology has become an important emerging technology with rapid development and wide application in the information industry. It is widely used in the fields of smart city, smart transportation, smart home, smart medical treatment and smart phone. Embedded technology combines computer science and technology, electronic information engineering, communication engineering, Internet of Things engineering and other disciplines, so the professionalism and systemic nature of embedded technology is very complicated. Therefore, the design of the embedded technology curriculum system should be based on the embedded system as a whole, comprehensively considering the hardware and software requirements of the embedded technology, and the course should be considered systematically, rather than just reforming a single course.

\section{Course Development Method Oriented to Professional Ability}

In the traditional professional curriculum[2], the curriculum often emphasizes too much on the integrity and systematicness of the knowledge system, emphasizes knowledge training, and neglects ability and skill training. It does not pay enough attention to the application and practical ability training. As a result, the course positioning has not been in line with the market, nor has it been integrated with the actual needs of the enterprise. The course teaching content does not reflect the latest trends of industry development, and it has not directly connected with the needs of students 'employment. Insufficient attention is paid to the teaching system and engineering practice, resulting in insufficient application and practical ability of graduates and weak competitive advantage. 
Moreover, the lack of organic links between the various courses, the fragmentation of knowledge, and the lack of overall design have led to the inability of multi-course teaching to form a common goal and poor teaching effectiveness.

Based on professional ability-oriented curriculum group development method, the curriculum group is determined according to the needs of job capabilities. First, the job positions that the students are engaged in after graduation are determined based on the professional training goals; then the job tasks performed by the posts are determined according to the job positions; The content and the knowledge, abilities and professional qualities required to complete the work content are obtained, and these skills, knowledge and quality requirements are taken as the teaching goals and the learning goals of the students; finally, the corresponding courses are derived according to these requirements to form a curriculum group. The development steps are shown in Figure 1.

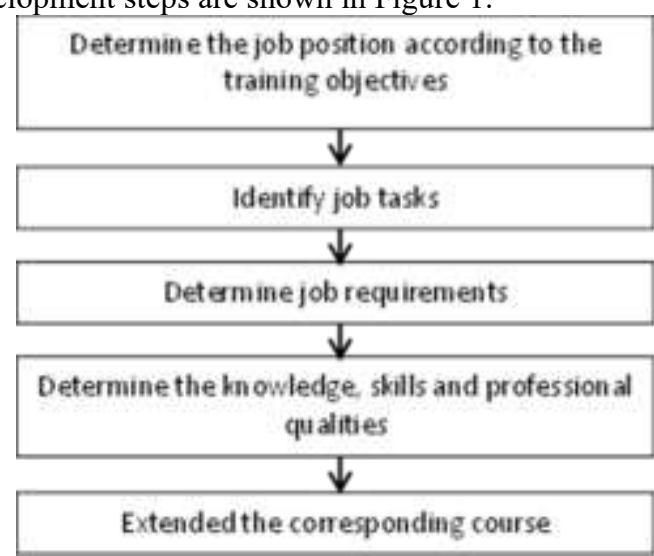

Figure 1. Course Development Process Based on Professional Ability Orientation

\section{The Development of Embedded Technology Applied Course Group}

With the continuous expansion of the connotation and extension of embedded technology, the traditional curriculum can no longer meet the training requirements of embedded technology talents. In the current curriculum of information technology majors, embedded technology courses often also face the problem of focusing on knowledge rather than ability, and paying insufficient attention to application and practical ability training. Therefore, it is imperative to strengthen the construction of embedded technology application-oriented courses. On the one hand, students' complete embedded system development ability needs an application-oriented curriculum group with a connection between before and after as a teaching support to avoid arbitrary and fragmented curriculum. On the other hand, in the construction of new engineering majors in information technology, new engineering talents are particularly required to have the ability to solve complex engineering problems. Embedded system development is one of the key engineering issues. It is necessary to provide students with relevant "problem solving" capabilities through the overall application-based curriculum group[3].

The training goal of application-oriented undergraduate embedded technology direction is to have embedded development talents with the ability to solve complex engineering problems. A total of job positions include hardware maintenance engineers, software and hardware test engineers, single-chip microcomputer development engineer, embedded system development engineers, etc. This article takes the single-chip microcomputer development engineer as an example to illustrate the development process of the embedded curriculum group[4].

(1) The task of the single-chip microcomputer development engineer is to engage in the analysis, programming, design, integration, maintenance, evaluation, and improvement of hardware development applications and automation control systems.

(2) The work includes: SCM control program writing; digital-analog mixed circuit design; PCB design; hardware welding, etc.

(3) The required knowledge, skills and professional qualities include: C51 knowledge and programming ability; analysis and design of electronic circuits; PCB drawing; familiar with the performance indicators and selection of related components; microcontroller development capabilities; communication design; using simulation tools Software and hardware testing; skilled use of welding tools; good communication skills and hands-on skills. (There is no subdivision of knowledge ability and professional accomplishment here).

(4) The extended corresponding courses include:

Professional basic courses: analog electronic technology, digital electronic technology, electronic circuit design.

Professional compulsory courses: C language programming, microcomputer principle and interface technology, single chip microcomputer development and application, PCB drawing, computer network

Professional direction courses: comprehensive training on embedded system development and hardware product development projects.

\section{Implementation of Embedded Technology Applied Course Group}

Based on the development process of the embedded technology curriculum group oriented by professional ability, the knowledge points and skill points corresponding to the courses and the future job requirements of the students can be introduced to determine the students 'learning goals and teachers' teaching goals. The teaching objectives of all courses revolve around the development of single-chip products.

(1) Learning in the actual environment

According to the realization needs of course knowledge, skills and professional literacy, design real work situations, 
and arrange them in order from easy to difficult. In the teaching process, according to the working steps to determine the learning sequence of the course content is to achieve the structure of the course content, the teaching process here is actually the process of the application of knowledge and ability. Different knowledge abilities are gradually developed, and the same knowledge abilities are from shallow to deep. For example, the study of digital and analog circuits in professional basic courses can design some simple electronic products, allowing students to master the design of digital and analog mixed circuits, from designing circuits to the final circuit board welding, allowing students to complete the design process of electronic products Study theory while training practical skills. The courses in the professional compulsory course stage take the development of embedded systems as the core of the single-chip microcomputer as a real working situation. The courses related to interface technology, communication technology, software programming and PCB drawing are integrated through the development of electronic products based on single-chip microcomputers. The production process of multiple real situations is gradually deepened in the course learning.

(2) Student-centered classroom teaching

Teachers need to change their teaching ideas and adopt flexible and diverse teaching methods[5], such as teacher-student interaction, debate, on-site simulation, flipped classroom, micro-class, and MO-teaching. Based on the flexible use of the above teaching methods, students are given sufficient free time and space to inspire students to be responsible for themselves. The specific process is as follows:

1) First, the teacher issues the project task book before the class, and asks the students to consult the data after class to analyze the task book, including determining the task goal, querying important components, completing the preliminary project design plan, and drawing the project flow chart;

2) In the classroom, teachers explain the relevant knowledge points of the project, help students better understand the project, enable students to check for vacancies and find problems in their own design plans, students discuss in groups and modify the plan Form the final plan;

3) Entering the task implementation stage, the teacher conducts patrolling and answering and explaining common problems. Students follow the real process of electronic product design to carry out circuit design, program design and joint debugging of software and hardware. Questions are asked in a timely manner. Large knowledge points, teachers record and give a unified explanation at an appropriate time. We also put forward requirements for the teacher's explanation process, generally no more than 15 minutes, reflecting one-third of the teaching philosophy, that is, one-third of the teachers teach One is self-study, one-third hands-on practice, to achieve the teaching idea of "integration of teaching". If it is overtime, we will think that the project design is not detailed enough, and the project will be decomposed again in the later stage to reduce the difficulty of the project, which is also one of the basis for the continuous reform of our curriculum construction;

4) The next step is hardware welding and product testing. Students perform hardware welding on the successfully simulated works. After the welding is completed, the students test the works to ensure that the project functions are completed and the expected requirements are met. In addition, we require students to report, including work simulation and physical demonstration, to truly evaluate the learning outcomes by the project. In this middle, there will be PK between different groups, and the student 's achievements will be determined through the mutual evaluation of students and teacher evaluation;

5) Finally, it is project expansion. We will carry out additional tasks for students who have the abilities to learn. Most of them are based on existing projects to expand independently to train students' innovative ability.

Students continue to repeat the entire work process, repeating the steps, the difference is the gradual deepening of the course content. The teacher only serves as a guide to give the classroom to the students, so that the student-centered work process can be systematically taught Not only to enable students to master knowledge, but also to cultivate students' ability to analyze and solve problems and innovative thinking.

\section{Conclusion}

Based on the requirements of the Ministry of education for the quality of curriculum teaching and the practice of embedded technology, this research focuses on the training of applied technology talents, aiming at the training of students' post professional ability, and studies and constructs an embedded curriculum group suitable for the training of complete embedded system development ability. The construction of this course group is suitable for the promotion of the information course group in the application-oriented colleges and universities. It is very helpful for the application-oriented colleges and universities to make clear the training objectives and improve the students' professional quality and post holding ability.

\section{ACKNOWLEDGMENT}

This research was financially supported by the Xi'an Peihua University 's 2019 school-level "Teaching and Practice Comprehensive Research Project" research project-Research and Implementation of the Construction of Embedded Technology Applied Curriculum Group for professional Ability Training (PHJG1905). 


\section{REFERENCES}

[1] Wang Nanlan, Li Jianqi, Wang Wenhu, Embedded System Curriculum Group under the Background of Innovation and Entrepreneurship--Exploration of Integrated Teaching System, China Electronic Education, 2019.1

[2] Tao Jili, Li Lingong, Cai Weiming, Wang Lang, Wang Zhuoyuan Reform of Embedded Curriculum System Based on Cultivation of Complex Engineering Problem Ability, Journal of Anhui Vocational College of Electronics and Information Technology, 2018.6

[3] Chen Jing, Exploration of Teaching System for Applied Undergraduate Embedded System Development Curriculum, Education Modernization, 2018.5

[4] Liu Haicheng, Zhou Haiying, Tong Ningning, Research on the structure and cultivation of the capacity of embedded development engineers, industry forum, 2016.8

[5] Zhou Ziang, Xu Yukun, He Yali, Research and Practice of Embedded System Curriculum Group Based on OBE Concept in the New Engineering Background, Journal of Zhoukou Normal University, 2019.9 